\title{
Arbor
}

\section{La cohesión social en la Corona de Castilla en tiempos de Isabel la Católica}

\section{Julio Valdeón Baruque}

Arbor CLXXVIII, 701 (Mayo 2004), 53-66 pp.

Isabel I de Castilla, más conocida como Isabel la Católica, comenzó su reinado a finales del año 1474. Su conclusión tuvo lugar el 26 de noviembre del año 1504, fecha en la que falleció, en la villa de Medina del Campo. Sin duda alguna su reinado fue de excepcional importancia, no sólo porque con su matrimonio con Fernando de Aragón se diera un paso decisivo para la creación de la monarquía hispánica, sino también porque en aquellos años se conquistó el reino nazarí de Granada, último reducto del Islam peninsular, al tiempo que el marino genovés Cristóbal Colón, ayudado por los Reyes Católicos, descubrió un nuevo continente, al que se denominaría América. En otro orden de cosas el reinado al que nos referimos conoció la normalización de la lengua castellana, obra del humanista Elio Antonio de Nebrija, así como la expansión de la imprenta, cuyo primer libro, el «Sinodal de Aguiloafuente», se había impreso en España en 1472, es decir dos años antes de la proclamación de Isabel como reina de la corona de Castilla.

No obstante el aspecto que vamos a desarrollar en este texto se limita al análisis de los problemas que planteaba la sociedad de aquellos años, en concreto en la corona de Castilla, territorio al que accedió como reina Isabel la Católica. Por de pronto hay un hecho que llama la atención de todos los estudiosos de aquella época. En contraste con las crecientes tensiones sociales que se habían producido durante el reinado de Enrique IV, hermano y antecesor de Isabel, así por ejemplo la denominada «segunda guerra irmandiña», que tuvo como escenario la región de Galicia, o las tremendas luchas de bandos que se desarrollaron en el País 
Vasco, la etapa en la que fue reina Isabel I se caracterizó, al margen de algunos acontecimientos aislados, como lo sucedido en la localidad cordobesa de Fuenteovejuna, por el predominio de la paz. ¿No dijo, algunos años más tarde, el destacado cronista Gonzalo Fernández de Oviedo, en referencia al reinado de los Reyes Católicos que «aquel fue un tiempo áureo y de justicia»? Por su parte otro conocido cronista, en este caso Andrés Bernáldez, coetáneo de los Reyes Católicos, indicó que la España de Isabel I de Castilla y Fernando II de Aragón se caracterizó por la «mucha paz y concordia y justicia».

La sociedad de finales del siglo XV y comienzos del XVI, como es bien sabido, estaba articulada en tres estamentos, dos de ellos privilegiados, el de la nobleza y el de los eclesiásticos, y un tercero, denominado de los «laboratores» o si se quiere el «tercer estado» sobre el cual, aparte de no gozar de privilegios, recaían todos los trabajos necesarios para el funcionamiento de los reinos. Los nobles tenían como función la dedicación a las armas y los clérigos procurar conducir al pueblo hacia Dios. Es preciso señalar, no obstante, que el ámbito del tercer estado, sin duda el estamento que incluía a la mayor parte de la población de aquellos tiempos, se había diversificado en los siglos anteriores, pues al lado del mundo de los campesinos, por supuesto el mayoritario, se fue desarrollando el sector urbano. Es más, en las ciudades y villas, dedicadas preferentemente a las actividades artesanales y comerciales, se produjo a lo largo de la Edad Media una significativa división entre los sectores dominantes, por una parte, lo que se llamará a fines del Medievo la «oligarquía urbana», o, según la expresión de la historiadora Carmen Carlé los «caballeros patricios», y por otra los grupos populares, el llamado «estado llano» o la «gente menuda».

El análisis de la «cohesión social» de aquel reinado vamos a concretarlo en diversos aspectos. De entrada hablaremos de la actitud adoptada por Isabel la Católica con respecto al mundo de la alta nobleza. A continuación estudiaremos la conexión de Isabel I de Castilla con el ámbito urbano. El tercer aspecto tiene que ver con el sector del campesinado. Por último aludiremos también al problema planteado por las minorías, es decir los judíos y los mudéjares.

\section{Isabel la Católica y la alta nobleza}

La historiografía tradicional puso de manifiesto que los Reyes Católicos en general, e Isabel I de Castilla en particular, protagonizaron una 
política de claros tintes antinobiliarios. Al mismo tiempo se presentaba a los mencionados monarcas como protectores de la incipiente burguesía urbana. Este punto de vista, justo es señalarlo, ha desaparecido de la más reciente y más brillante historiografía, comenzando por los excelentes trabajos del profesor Luis Suárez Fernández. El papel de la alta nobleza, no nos engañemos, era de todo punto fundamental en aquel tiempo. Estamos hablando de los «defensores» de la sociedad, los cuales, según podemos leer en las «Partidas» de Alfonso X el Sabio, destacaban por el esfuerzo, la honra y el poderío. ¿No se dijo en las Cortes celebradas en la ciudad de Burgos en el año 1379 que a los nobles era imprescindible honrarles por «la nobleza del linaje...la bondad... [y] el pro que de ellos viene»? Asimismo en las Cortes reunidas en la localidad de Briviesca en el año 1387 se afirmó que la nobleza era la «cabeza por la que se rigen y gobiernan los otros miembros corporales». Es más, los textos de la Baja Edad Media presentan, como rasgos singulares que caracterizaban a la nobleza, el espíritu de servicio, la lealtad y la caballerosidad, aun cuando también se les atribuyeran algunos defectos, así el orgullo y la soberbia. Ahora bien, en tiempos de los Reyes Católicos se puso fin al duro enfrentamiento que, desde las últimas décadas del siglo XV, habían mantenido la monarquía y la nobleza, tema estudiado magistralmente por el citado profesor Suárez Fernández. La conclusión de aquella pugna fue, según dice el profesor Suárez, la victoria de los dos contendientes, pues la nobleza logró mantener «el fortalecimiento económico y social», al tiempo que la monarquía "pudo recobrar su poder absoluto en el orden político».

La alta nobleza, más conocida como el conjunto de los «ricos omes», había logrado, desde el acceso al trono del primer monarca de la dinastía Trastámara, Enrique II, un notable afianzamiento, sobre todo en lo que se refiere a su papel en el terreno económico y social. No sólo se otorgaron numerosas mercedes a los poderosos, la «ventosa señorial», según la irónica expresión utilizada por el eminente historiador D.Claudio Sánchez Albornoz, sino que, desde el año 1390, los mencionados dominios señoriales pasaban íntegros a los descendientes, gracias a la aprobación del sistema jurídico del mayorazgo. Al mismo tiempo los magnates nobiliarios poseían, no lo olvidemos, derechos jurisdiccionales en sus tierras. ¿No se ha dicho en diversas ocasiones que las cortes de los grandes magnates nobiliarios reproducían, aunque lógicamente en un estado mucho menor, el mundo específico de la propia corte regia? Entre los linajes más relevantes de las décadas finales del siglo XV cabe mencionar, por citar sólo a unos cuantos, a los Mendoza, los Estúñiga, los Manrique, los Ve- 
lasco, los Pimentel, los Enríquez, los Guzmán o los Ponce de León. Algunos de dichos linajes pertenecían a lo que el profesor Salvador de Moxó denominó en su día la «nobleza vieja, en tanto que los restantes eran protagonistas de la «nobleza nueva», es decir la que había prosperado de la mano de la dinastía Trastámara. Los mencionados linajes nobiliarios poseían extensos dominios territoriales, situados tanto en la Meseta norte (caso de los Manrique, los Velasco y los Pimentel) y sur (así los Mendoza y los Estúñiga) como en el valle del Guadalquivir (en donde se hallaban los Guzmán y los Ponce de León). Ni que decir tiene que también los obispados, los monasterios y las Órdenes Militares poseían amplios señoríos.

Es indudable que los Reyes Católicos, y concretamente Isabel la Católica por lo que respecta a la corona de Castilla, respetaron a los miembros de los grandes linajes nobiliarios. Otra cosa muy distinta es que, a la hora de buscar colaboradores para el desempeño de sus tareas políticas, los monarcas se fijaran ante todo en los «letrados», es decir en los expertos en cuestiones jurídicas. Estamos hablando de aquellas personas que, al margen de su condición social, habían cursado estudios de Derecho en las Universidades de la época. De esa manera, como ha señalado sin duda acertadamente el profesor de Historia del Derecho David Torres, se daban importantes pasos hacia la «objetivación» del poder político. Así se deduce, por ejemplo, analizando el funcionamiento de la casa y corte de la reina Isabel la Católica, organismos que contrastan de forma paladina con lo que habían sido en tiempos del anterior monarca, es decir de Enrique IV.

Ciertamente hubo algunas víctimas nobiliarias en tiempo de los Reyes Católicos. Tal fue el caso, por ejemplo, del magnate gallego Pardo de Cela, el cual perdió la vida como consecuencia de la aplicación de la justicia regia. Asimismo en las famosas Cortes de Toledo del año 1480 los Reyes Católicos tomaron la decisión de recortar buena parte de las mercedes que, de forma un tanto alocada, había otorgado a la nobleza durante su reinado el sin duda débil monarca castellano Enrique IV. De esa forma, como señaló el cronista Hernando del Pulgar, se buscaba «restituir el patrimonio real, que estaba enagenado de tal manera que el Rey é la Reyna no tenían tantas rentas como eran necesarias para sostener el estado real é del Príncipe é Infantes sus fijos. E ansimesmo para las cosas que se requerían expender cada año en la administración de la justicia é buena gobernación de sus reynos». ¿Quiénes fueron los principales perjudicados de aquella significativa medida tomada en las Cortes de Toledo de 1480? Ante todo diversos magnates nobiliarios que, en los años anteriores, habían apoyado, en la guerra de sucesión que vivió la corona 
La cohesión social en la Corona de Castilla en tiempos...

de Castilla, la causa de Juana la Beltraneja frente a los ejércitos que defendían a Isabel la Católica. Dichos nobles, a tenor de los estudios realizados, sufrieron espectaculares recortes en sus rentas, por lo general superiores al $60 \%$. Por el contrario, los magnates nobiliarios que habían apoyado en la citada contienda la causa de la reina Isabel apenas perdieron nada de las rentas que percibían. Por lo tanto no se trataba, ni mucho menos, de una política de signo antinobiliario, sino simplemente de un intento de fortalecer la hacienda regia, al tiempo que se castigaba a quienes en su día habían participado, en el año 1465, en el tragicómico suceso conocido como la «farsa de Ávila» y, posteriormente, habían peleado contra Isabel I de Castilla en aquella dramática guerra de sucesión, a la que se puso fin con la paz de Alcaçovas del año 1479.

No podemos dejar de mencionar, como dato de notable relieve, la creación, por parte de los Reyes Católicos, de nuevos señoríos situados en la corona de Castilla, lo que pone de manifiesto su deseo de beneficiar a determinados magnates de la alta nobleza. Entre ellos destacan el de los Vélez, ubicado en el reino de Granada, señorío que fue otorgado a los Fajardo, una familia nobiliaria de origen murciano, y el de Maqueda, que se hallaba en las tierras toledanas. Al mismo tiempo los reyes Católicos concedieron a algunos magnates nobiliarios pomposos títulos, entre ellos el ducado del Infantado, que recibieron los Mendoza, una familia caracterizada desde bastante tiempo atrás por su constante apoyo a la causa regia, así como los ducados de Nájera y de Gandía, y el marquesado de Moya.

\section{Isabel la Católica y el mundo urbano}

No es posible dejar de lado al mundo de las ciudades y villas, las cuales, justo es señalarlo, se hallaban, en el reinado de los Reyes Católicos, en una etapa de indudable apogeo. Como antes dijimos las principales actividades de las ciudades y villas eran la producción artesanal y la práctica mercantil. En el ámbito de la corona de Castilla una de las ciudades que se encontraba a la cabeza, al menos desde la perspectiva del comercio, era Burgos. Allí funcionaba desde años atrás una muy significativa «universidad de mercaderes». Pero el principal paso lo alcanzó en el reinado de Isabel I de Castilla, en concreto en el año 1494, fecha en la cual se estableció en la caput Castellae un Consulado. Burgos era, sin duda alguna, el lugar esencial en el que se preparaban las exportaciones que se orientaban hacia la zona de Flandes y, en general, hacia la costa atlánti- 
ca europea. En el otro extremo de la corona de Castilla nos encontramos con Sevilla, una urbe en la que desempeñaban un papel primordial los hombres de negocios genoveses allí establecidos, protagonistas de un activo y próspero comercio que se proyectaba tanto hacia el mar Mediterráneo como hacia el norte de África. Por otra parte no hay que dejar de mencionar a la villa de Medina del Campo. Allí se habían creado, a comienzos del siglo XV, unas ferias, las cuales terminarían por ser, sin duda alguna, las más importantes de toda la corona de Castilla. Precisamente en el año 1491 los Reyes Católicos las denominaron «ferias generales del reino». En otro orden de cosas es preciso citar a Bilbao, puerto por excelencia en lo que se refiere a la exportación, por el Atlántico, de lana, hierro y otros productos originarios de la corona de Castilla. Ahora bien, el auge que había experimentado el comercio en la corona de Castilla, particularmente en el transcurso del siglo XV, contrastaba con la parálisis de la industria. El conocido historiador Ramón Carande habló en su día, en referencia a la actividad textil de la corona de Castilla a finales del siglo XV, de una «postrada industria».

Junto a las actividades económicas los núcleos urbanos eran, asimismo, centros básicos por lo que se refiere a la actividad política de la época. El caso más significativo nos lo ofrece, por supuesto, la villa de Valladolid. Allí había nacido el monarca Enrique IV y allí tuvo lugar, en el año 1469, el matrimonio de Isabel y Fernando, los futuros herederos de las coronas de Castilla y de Aragón. Por otra parte, Valladolid fue la localidad en donde se decidió establecer, a mediados de la decimoquinta centuria, la Chancillería, especie de Tribunal Supremo de Justicia. Valladolid fue también la villa en donde se celebró, a lo largo del siglo XV, mayor número de reuniones de la institución de las Cortes. No obstante lo más llamativo fue el hecho indiscutible de la presencia habitual de la Corte, en aquellos años, en la villa de Valladolid, la cual se convirtió, sino de iure, sí de facto en el auténtico centro político de la corona de Castilla. Aquella circunstancia explica que algunos magnates nobiliarios, caso entre otros de los Pimentel, decidieran poseer una residencia en Valladolid, con el propósito de vivir cercanos al entorno cortesano. Si cambiamos de tema, y pasamos del mundo de la política al de la vida intelectual, llegaremos a la conclusión de que en la cuenca del Duero se hallaban nada menos que las dos principales universidades de todo el territorio hispano. La más antigua universidad era la de Salamanca, que databa de comienzos del siglo XIII, cuando era rey de León Alfonso IX. Algún tiempo después, en concreto a mediados del siglo XIV, se erigió una segunda universidad, cuya sede era la villa de Valladolid. 
Las ciudades y villas estaban estrechamente ligadas con la institución de las Cortes. Las más antiguas Cortes, a las que acudían la nobleza, el clero y el tercer estado, fueron, como es sabido, las de León del año 1188. De todos modos lo más llamativo es que en el siglo XV el papel protagonista de las cortes lo desempeñaban los procuradores de las ciudades y villas, en tanto que los magnates nobiliarios y los altos dignatarios de la Iglesia apenas se interesaban por esa institución. Eso significa que las Cortes de la segunda mitad del siglo XV fueran, básicamente, un lugar de debate entre los reyes, por una parte, y las ciudades y villas, por otra. Eso sí, las Cortes del siglo XV sólo contaban con procuradores de diecisiete ciudades y villas. Más de la mitad de dichos núcleos urbanos, nueve en concreto, se hallaban en la Meseta norte. Las restantes ciudades y villas presentes en las Cortes eran originarias de la Meseta sur, Andalucía Bética y el reino de Murcia. No obstante, a raíz de la conquista por los cristianos del reino nazarí, se añadió a las Cortes la representación de una nueva ciudad. Nos referimos, obviamente, a Granada.

$\mathrm{Al}$ frente de los núcleos urbanos se hallaba, desde tiempos del monarca del siglo XIV Alfonso XI, el regimiento. Los regidores, cuyo cargo se mantenía mientras viviesen sus titulares, eran nombrados por los reyes. De todos modos los regidores, no lo olvidemos, eran miembros de las más poderosas familias urbanas. ¿No se ha hablado, por parte de la historiografía, de las «oligarquías urbanas», precisamente para aludir al sector que controlaba los concejos? Eso sí, la citada oligarquía integraba tanto a individuos pertenecientes a la nobleza local, es decir a caballeros, como a destacados hombres de negocios. Estudios recientes, como los de María Asenjo a propósito de la ciudad de Segovia, o los de Juan Antonio Bonachía e Hilario Casado sobre Burgos, han demostrado la conexión que llegó a establecerse entre lo que podríamos denominar la nobleza urbana y la incipiente burguesía. Así pues se produjo una especie de maridaje entre la riqueza y la caballería. Eso sí, en tiempo de los Reyes Católicos se generalizó el sistema de los corregidores, representantes directos de los reyes en las ciudades y villas de sus reinos.

En el otro extremo de los núcleos urbanos se hallaba la denominada "gente menuda», sin duda el grupo mayoritario en términos cuantitativos. Eran los artesanos, los pequeños mercaderes, los menestrales, los jornaleros o los criados. Estamos hablando de personas que vivían de su trabajo pero que estaban totalmente excluídas de los cargos de gobierno del concejo. Por debajo de estas gentes nos encontramos con el mundo de la pobreza y de los marginados. En tiempo de «malos años»o de difusión de terribles epidemias se incrementaba notablemente ese sector, debido 
a que individuos del «común» podían caer en el terreno de los menesterosos. En cualquier caso el reinado de los Reyes Católicos no conoció desastres tan lamentables como los que se habían producido años atrás, particularmente en el siglo XIV.

Tenemos diversos testimonios que ponen de manifiesto el apoyo prestado por los Reyes Católicos, y ante todo por Isabel I de Castilla, a determinados núcleos urbanos. Uno de los ejemplos más significativos nos lo ofrece la ciudad de Segovia. Un insigne colaborador de los Reyes Católicos, Andrés Cabrera, personaje converso, recibió de los Reyes Católicos, en el año 1480, diversas tierras del alfoz segoviano, en concreto los sexmos de Valdemoros y Casarrubios, en los que vivían alrededor de unos 1.200 vasallos. La ciudad de Segovia no vio con buenos ojos aquella donación regia, que le supuso una merma en cuanto a su jurisdicción. Paralelamente nos consta que Andrés Cabrera, el señor de aquellos lugares, desarrolló una política expansiva por el ámbito segoviano. La gravedad que llegaron a alcanzar aquellos actos derivaron en el hecho de que la reina Isabel revocara en su testamento las mercedes concedidas a Andrés Cabrera en las tierras segovianas. Estamos hablando de un hecho trascendental, que pone de relieve la inequívoca actuación regia en defensa de las ciudades de sus reinos. Eso sí, Andrés Cabrera recibió, como compensación, varias concesiones en el recién incorporado reino de Granada.

Otra ciudad que llegó a ser perjudicada, terminando los Reyes Católicos por salir en su defensa, fue Burgos. Diversos lugares que dependían de la jurisdicción del concejo burgalés terminaron cayendo en manos de familias de la alta nobleza. Tal fue el caso de los núcleos de Pancorbo y de Miranda de Ebro, cuyo control pasó a la familia Sarmiento, de la plaza fuerte de Muñó, dominada finalmente por los Rojas, o del castillo de Lara, que pasó al linaje de los Cartagena. La ciudad de Burgos no acató de buen grado aquellos acontecimientos, que supusieron para ella un durísimo golpe. Ahora bien, en el año 1506, es decir dos después del fallecimiento de Isabel la Católica, el corregidor de Burgos pidió al Consejo Real que devolviera al concejo de la ciudad de Burgos el control de todos aquellos lugares, es decir Pancorbo, Miranda de Ebro, Muñó y Lara.

Conflictos entre las ciudades y la alta nobleza, acaso el precedente de la revolución de las Comunidades, que estalló en la corona de Castilla algunos años después, según el punto de vista del historiador norteamericano S. Haliczer, se produjeron en otros varios lugares. Esa pugna se produjo, por ejemplo, en Toledo, magistralmente estudiada por el profesor francés J. P. Molenat, pero también en Valladolid, villa que estaba alar- 
La cohesión social en la Corona de Castilla en tiempos...

mada por la expansión de la alta nobleza a través de su alfoz, en Cuenca, que presentó en el año 1502 una demanda al Consejo Real en protesta de los zarpazos señoriales que estaba sufriendo, en Soria, a la que le sustrajeron ocho aldeas, y en Badajoz, que seguía pleiteando por las pérdidas de Feria, Zafra y La Parra. Ahora bien, a tenor de los ejemplos de Segovia y de Burgos podemos llegar a la conclusión de que los monarcas, deseosos de alcanzar en sus reinos la paz, no dudaron en salir en defensa de los núcleos urbanos. De esa forma se daban importantes pasos para lograr una cohesión social en sus reinos.

\section{Isabel la Católica y la «gente menuda».}

En tiempos de los Reyes Católicos predominó la paz social. Ahora bien, ello no fue óbice para que se produjeran algunos conflictos sociales, particularmente en el mundo rural. Sin duda el conflicto más llamativo de aquel reinado fue el que tuvo lugar, en el año 1476, en la localidad cordobesa de Fuenteovejuna, tema inmortalizado por el genial escritor Lope de Vega. Fuenteovejuna, en el pasado núcleo situado en los dominios del concejo cordobés, por lo tanto integrada en el realengo, pasó a depender, en el año 1464, de la Orden militar de Calatrava. Unos años más tarde, en 1476, los vecinos de dicha localidad se amotinaron contra su comendador, Fernán Pérez de Guzmán, que terminó siendo asesinado. El cronista Alonso de Palencia afirma que los rústicos de Fuenteovejuna estaban "sedientos de sangre del Comendador», indicando, unas líneas más adelante, que tras irrumpir en su casa uno de dichos rústicos «superando a todos en crueldad, torció el hierro de la lanza en el cráneo del comendador... Enseguida los feroces rústicos hundieron sus puñales en el pecho y en el rostro del herido, que cayó al suelo sin vida. Luego arrojaron por la ventana el cuerpo medio destrozado a la calle, donde las turbas acabaron por despedazarle a golpes y a pedradas». Eso sí, los revoltosos de aquella villa cordobesa gritaban por las calles vivas a los reyes Isabel y Fernando. En definitiva, se quejaban con gran amargura del señor del que dependían directamente, pero veneraban a los monarcas de sus reinos, cuyo poder procedía directamente del Altísimo.

No cabe duda de que el mundo del campesinado era, en la corona de Castilla de finales del siglo XV, muy variado. Había incluso «campesinos hacendados», expresión utilizada en su día por el profesor Salvador de Moxó. Pero el sector predominante era, sin duda alguna, el de los campesinos dependientes, que trabajaban en tierras ajenas, ya fueran de la 
nobleza o de la Iglesia. Esos labriegos gozaban del derecho de usufructo, lo que suponía que podían transmitir a sus descendientes el trabajo de la tierra. Pero, a la vez, estaban obligados a una gran variedad de tributos, al tiempo que dependían jurisdiccionalmente de su señor. El contraste entre los grandes propietarios de la tierra y los campesinos dependientes lo puso de manifiesto una obra literaria que data de finales del siglo XIV. Me refiero al denominado Libro de Miseria de omne, en el cual puede leerse lo siguiente:

«el siervo con el señor non andan bien acompañón nin el pobre con el rico non partirá bien quiñón, nin será bien segurada oveja con el león».

En el reinado de los Reyes Católicos hubo diversos conflictos en el mundo rural, pero por lo general fueron de escasa trascendencia, lo que contrasta rotundamente con las etapas anteriores. Es más, en algunos casos tenemos noticias de la actuación, a favor de los labriegos, por parte del poder regio. Veamos algunos ejemplos. En el año 1482 los labradores del valle de Léniz, situado en Guipúzcoa, presentaron en la Chancillería de Valladolid un memorial de agravios contra el señor de Oñate, del que eran dependientes. Cuatro años después, en 1486, la Chancillería dictó una sentencia favorable a los campesinos del valle de Léniz. Sabemos, por otra parte, que en el año 1484 los Reyes Católicos salieron en defensa de los concejos de la Merindad de Valdeburón, quejosos de las excesivas exigencias de su señor. Unos años después nos consta que los vecinos de la localidad de Ampudia reclamaron ante la autoridad regia la recuperación de los bienes comunales, que habían sido absorbidos por su señor, el conde de Salvatierra. Eso demuestra que los campesinos confiaban en la actuación de la justicia regia. A finales de la década de los noventa los habitantes de Caracena, localidad situada en tierras sorianas, presentaron a los Reyes Católicos un memorial de agravios en el que exponían los continuos abusos en los que incurría su señor, un tal Alonso Carrillo.

También tenemos noticias de la pugna que estalló, en el año 1491, en la localidad zamorana de Fuentelcarnero, entre los labriegos que habitaban aquel lugar y el monasterio cisterciense de Valparaíso, propietario de aquellas tierras. Los datos que poseemos de aquel conflicto provienen del sector monacal, es decir de los que fueron víctimas de la protesta. Un texto de aquel tiempo señala que los labriegos de Fuentelcarnero, «movidos [...] por diábolica persuasión ficieron repicar las campanas en el dicho lugar e [...] salieron todos [...] faziendo muy grand alboroto e sediçion, 
recodieron así armados con grandes gritos a donde estavan los dichos religiosos [...] con intençion e propósito de los matar, diziendo mueran los traidores, putos, erejes e otras palabras muy feas e injuriosas». Sin duda la imagen que se expone en este texto de los labriegos de aquel lugar no era nada positiva, pero no deja de reconocer el importante papel que podía desempeñar, en la lucha contra los señores de la tierra, la comunidad de los campesinos.

En el año de la muerte de la reina Isabel la Católica, 1504, nos consta que la localidad de Salvatierra, situada en tierras de Álava, presentó a los Reyes Católicos una queja por los excesivos tributos que el señor de dicha villa, a la sazón Pedro de Ayala, les exigía, sin duda muy superiores a lo que habitualmente entregaban en concepto de señorío. Una vez más se ponía de relieve la indudable confianza que los labriegos de la corona de Castilla tenían en el poder regio, del que esperaban que tomase medidas para tratar de evitar los abusos de los poderosos y, al mismo tiempo. Garantizar el estricto cumplimiento de la justicia.

\section{Isabel la Católica, los judíos y los conversos}

Hemos aludido a los diversos grupos sociales que existían dentro de la comunidad cristiana de la corona de Castilla. Pero en dicho territorio había también minorías religiosas, los hebreos y los mudéjares, las cuales gozaban de una cierta autonomía, si bien el panorama se les había ido cerrando desde el siglo XIV. Sin duda las diferencias de los judíos y de los mudéjares con los cristianos eran de naturaleza religiosa, pero la comunicación entre las gentes de las tres religiones citadas no dejaba de ofrecer rasgos de carácter social. De todos modos el grupo que más preocupaba a los cristianos era el de los judíos, a los que se acusaba de «deicidas», es decir asesinos de Jesucristo. Paralelamente se lanzaban duros ataques contra los hebreos, a quienes se tachaba de practicar la usura. En verdad los judíos que se dedicaban a las actividades financieras eran una minoría, pero como es habitual se acusaba a toda la comunidad hebraica de lo que sólo afectaba a un pequeño sector.

Eso sí, los judíos eran denominados servi regis, lo que suponía que los monarcas podían utilizarlos pero a la vez se veían obligados a protegerlos. En la corte regia encontramos a hebreos en puestos destacados, del mundo de las finanzas, desde finales del siglo XI, cuando era rey de Castilla y León Alfonso VI. A partir de entonces se fue creando un clima hostil contra la minoría judía a nivel popular. No obstante, fue en el siglo 
XIV cuando ese clima se expandió por los territorios de la corona de Castilla. La difusión de la peste negra, de la que se acusaba a los judíos, la guerra fratricida entre Pedro I y su hermanastro Enrique de Trastámara, en la que éste, finalmente vencedor, acusaba al rey de Castilla de projudío y, como remate, los dramáticos sucesos del año 1391, derivados de las terribles prédicas del clérigo Ferrán Martínez, contribuyeron a acrecentar la hostilidad contra los hebreos. En verdad, a raíz de los sucesos de 1391, muchos judíos aceptaron el bautismo cristiano. También contribuyeron al paso del judaísmo al cristianismo las predicaciones del dominico valenciano Vicente Ferrer.

Ahora bien, la comunidad judaica había experimentado un notable descenso en las últimas décadas del siglo XV. Ello fue la consecuencia de la conversión de una gran cantidad de hebreos al cristianismo. Se les denominaba judeoconversos, cristianos nuevos o «marranos». De hecho en el siglo XV, como indicó en su día el profesor Eloy Benito Ruano, en las tierras hispanas se pasó del problema judío al problema converso. ¿Qué quería decirse con ello? Pues que a los cristianos viejos les preocupaba la gran cantidad de conversos, los cuales no sólo seguían con sus viejas profesiones, sino que podían acceder a puestos de mando en los concejos (caso de los Marmolillo en Sevilla, los de la Rúa en Palencia o los Maluenda y los Cartagena en Burgos) e incluso contraer nupcias con algunos sectores de la nobleza. Un suceso muy llamativo se produjo en la ciudad de Toledo en el año 1449, testigo de una revuelta contra los conversos o cristianos nuevos. El punto de partida de aquel conflicto fue la protesta popular contra un tributo, del que era recaudador un tal Alonso de Cota, judeoconverso. Posteriormente la revuelta fue capitaneada por Pero Sarmiento, un personaje de la nobleza. El principal objetivo de los rebeldes era impedir que los judíos ocuparan cargos en el concejo toledano. Es más, la hostilidad contra los conversos alcanzó tales extremos que llegó a decirse de ellos que, independientemente de su sinceridad o no con el cristianismo, procedían del «ruin linaje de los judíos». ¿No es posible ver en esta expresión una manifestación de indudable cariz racista?

El clima de animadversión hacia los conversos continuó en los años siguientes. Recordemos los duros sucesos de los años 1473 y 1474, que se iniciaron en la zona de Córdoba, propagándose por el resto de la corona de Castilla, lo que explica que llegasen hasta Segovia y Valladolid. Paralelamente estaba creciendo la petición de instituir un tribunal inquisitorial para perseguir a los falsos conversos. Dicho tribunal fue finalmente autorizado por el pontífice Sixto IV, en el año 1478, a través de la bula titulada Exigit sincerae devotionis affectus. La Inquisición, 
cuyo objetivo esencial no era otro sino desenmascarar a aquellos conversos que, pese a su condición de cristianos, seguían judaizando, comenzó sus actuaciones en las tierras hispanas en el año 1480, en concreto en la ciudad de Sevilla. Como ha indicado el hispanista francés Bartolomé Bennassar la Inquisición a que nos referimos fue «un instrumento de la monarquía española».

¿En que situación se encontraban los judíos? Recordemos que en las Cortes de Toledo del año 1480 se tomó la decisión de obligar a los hebreos, así como a los mudéjares, de vivir en barrios aislados, totalmente separados de los cristianos. Al mismo tiempo no dejaban de circular, entre el pueblo cristiano, calumnias contra los judíos, a los que acusaban de cometer horrendos actos criminales. El caso más llamativo fue el denominado del Santo Niño de la Guardia, localidad situada en tierras toledanas. Algunos judíos fueron acusados, en torno al año 1490, de haber crucificado a un niño cristiano en la villa citada, así como de haber robado hostias con las que pretendían preparar un brebaje para envenenar a los cristianos. Al final se llevó a cabo un proceso judicial, pereciendo en la hoguera, en la ciudad de Ávila, el judío Yucé Franco y sus supuestos cómplices. De todos modos los investigadores de ese asunto han llegado a la conclusión de que esa crucifixión nunca existió. Lo cierto es que los hebreos eran vistos de forma sumamente negativa. ¿No se les representaba en las ilustraciones de la época con una desmedida nariz aguileña? ¿No se decía de ellos que eran cobardes, soberbios, rencorosos y vengativos? Al mismo tiempo se decía, por sorprendente que pueda parecer, que los caracteres hebraicos eran una clara expresión de la brujería. Eso sí, los reyes procuraban defenderlos, cosa que hicieron los Reyes Católicos en diferentes ocasiones. Resulta muy significativo, a este respecto, lo que dijo en su día el escritor hebreo Salomón ibn Verga, en su obra titulada La Vara de Judá: «Los judíos eran muy amados en España de los reyes, sabios, intelectuales y otras clases sociales, salvo del pueblo y de los monjes». En una línea semejante se sitúa el destacados historiador israelí de nuestros días Benzion Netanyahu, el cual manifiesta que en la corona de Castilla había, en la segunda mitad del siglo XV, un indudable clima de racismo, del que era protagonista el sector popular, y cuyos principales animadores eran los predicadores eclesiásticos.

No obstante, poco tiempo después de la conquista del reino de Granada, en concreto a finales de marzo del año 1492, se promulgó un edicto, por parte de los Reyes Católicos, en el que se establecía la expulsión de los judíos de las coronas de Castilla y de Aragón, salvo que aceptaran el bautismo cristiano. ¿Por qué se tomó dicha medida? Hay que tener en 


\section{Julio Valdeón Baruque}

cuenta que los judíos habían sido expulsados con anterioridad de numerosos territorios de la Europa cristiana. Al mismo tiempo es imprescindible aludir a la fuerte presión popular, así como de la Iglesia. Recordemos que, en el año 1485, los Reyes Católicos se dirigieron al corregidor de Segovia ordenándole que interviniese para tratar de impedir los duros sermones que lanzaba contra los judíos en dicha ciudad el monje dominico fray Antonio de la Peña. En cualquier caso todo parece indicar que fue el rey Fernando el Católico el que tomó aquella medida. Al parecer el destacado hebreo Isaac Abravanel, el cual terminó por abandonar Sefarad, intentó mediar a través de la reina Isabel la Católica para que no se decretara la expulsión de los judíos. De todos modos Isabel contestó a Abravanel lo siguiente: «¿Créeis que esto proviene de mí?», añadiendo a continuación: «El Señor ha puesto ese pensamiento en el corazón del Rey».

¿Se decidió expulsar a los judíos por motivos económicos, como a veces se ha señalado, o por cuestiones de naturaleza social? El motivo esencial de la expulsión de los judíos del ámbito hispánico tiene que ver, según ponen de manifiesto todos los indicios, con el deseo de evitar la comunicación de los cristianos nuevos con los hebreos. Esa idea la había defendido entre otros, años atrás, el provincial de los dominicos de Andalucía fray Miguel de Morillo, el cual pedía a los Reyes Católicos que impidiesen la comunicación entre los conversos y los judíos. Precisamente en el decreto de expulsión se alude al alto riesgo que suponía para los conversos o cristianos nuevos la posible relación con los que seguían adscritos a las creencias judaicas. Ahora bien, al ordenar la salida de los hebreos, excepto quienes aceptasen el bautismo cristiano, se avanzaba, aunque desde otra perspectiva, hacia la plena identificación de la monarquía hispánica con un determinado credo religioso, obviamente el cristiano, que era el mayoritario. Así las cosas se cumplía el conocido precepto de la época, el cual afirmaba aquello de cuius regio, eius religio. Por lo tanto se daba un nuevo e importante paso en orden a la cohesión social, al que seguiría, unos años más tarde, la expulsión de los mudéjares. En definitiva, como ha señalado Luis Suárez Fernández, se caminaba hacia el logro, en los reinos sobre los que gobernaban Isabel y Fernando, del «máximo religioso». 